\title{
Diseminasi Online Multimedia Pembelajaran Matematika yang Dikembangkan Menggunakan Videoscribe
}

\author{
Puji Astuti ${ }^{*}$, Febrian² \\ ${ }^{1,2}$ Universitas Maritim Raja Ali Haji, Tanjungpinang, Kepulauan Riau 29124, Indonesia \\ *e-mail korespondensi: pujiastuti@umrah.ac.id \\ Pengiriman: 1 November 2019; Diterima: 21 November 2019; Publikasi: 28 November 2019
}

\begin{abstract}
Abstrak
Tuntutan terhadap guru menghadapi era revolusi industri 4.0 adalah memanfaatkan teknologi informasi dan komunikasi (TIK) dalam pembelajaran. Selain kompetensi profesionalisme yang menuntut guru mampu mengembangkan media pembelajaran yang interaktif dan menarik agar terjadi peningkatan kualitas pembelajaran, guru juga perlu membaca peluang teknologi dalam penyebarluasan media. Tuntutan ini kiranya tak terpenuhi berdasarkan kondisi lapangan yang ditemukan yaitu belum ada guru di MGMP Matematika SMA dan SMK Kabupaten Bintan yang mengembangkan multimedia pembelajaran kemudian memanfaatkan teknologi seperti sosial media sebagai pengantar pembelajaran. Untuk itu, tim dosen Program Studi Pendidikan Matematika FKIP UMRAH melakukan kegiatan Pengabdian kepada Masyarakat $(\mathrm{PkM})$ berupa pendampingan diseminasi melalui sosial media (online) terhadap multimedia pembelajaran yang telah dikembangan dengan menggunakan program videoscribe dalam kegiatan PkM sebelumnya. Indikator keberhasilan kegiatan ini adalah keterlibatan aktif peserta selama kegiatan berlangsung yang dilihat dari observasi tim pelaksana PkM, multimedia pembelajaran yang dikembangkan guru didiseminasikan ke sosial media, dan hasil angket angket online melalui google form sebagai evaluasi kebermanfaatan kegiatan bagi peserta. Kegiatan PkM disimpulkan berjalan dengan baik karena 1) keterlibatan peserta (guru) $100 \%$ selama pendampingan; 2) dihasilkannya produk diseminasi video pembelajaran oleh guru peserta kegiatan di youtube channel; 3) penyampaian antusiasme guru peserta kegiatan agar diadakan lagi kegiatan pelatihan-pelatihan lainnya.
\end{abstract}

Kata kunci: pendidikan 4.0; video pembelajaran; videoscribe; e-learning

\begin{abstract}
In the industrial revolution 4.0 era, teacher needs to utilize information and communication technology (ICT) in learning. Beside the professionalism competencies proclaimed by teachers also require teachers to be able to develop interactive and interesting learning media so that there is an increase in the quality of learning, teachers also need to see potential through the use of technology in deliviering learning media. This challenge is inversely proportional to the conditions in the field, namely that there are no teachers in the Mathematics Teacher Association(MGMP) at SMA and SMK in Bintan Regency who develop learning multimedia and utilize technology such as social media as learning media. For this reason, Community Service (PkM) activities need to be conducted, with theme of online dissemination on learning multimedia developed by using videoscribe created through previous PkM program through social media (online). Indicators of the success of this activity is the active enggagement of the participants as seen from the observation during mentoring, the learning multimedias developed are disseminated to social media, and the results of online questionnaires via google form as the evaluation of the usefulness of the activities for the participants. From these indicators, the PkM activity was concluded to be going well because 1) 100\% participant (teacher) got involved during mentoring; 2) the production of learning video by teachers and the dissemination of the learning videos on the YouTube channel; 3) teacher participants require for more training activities.
\end{abstract}

Keywords: education 4.0; learning video; videoscribe; e-learning 


\section{Pendahuluan}

Tujuan pendidikan nasional tertuang dalam Undang-Undang (UU) No. 20 Tahun 2003 Pasal 3 menyebutkan Pendidikan nasional berfungsi mengembangkan kemampuan dan membentuk watak serta peradaban bangsa yang bermartabat dalam rangka mencerdaskan kehidupan bangsa, bertujuan untuk berkembangnya potensi peserta didik agar menjadi manusia yang beriman dan bertakwa kepada Tuhan Yang Maha Esa, berakhlak mulia, sehat, berilmu, cakap, kreatif, mandiri, dan menjadi warga negara yang demokratis serta bertanggung jawab (Departemen Pendidikan Nasional [Depdiknas], 2003). Amanat UU tersebut menyiratkan bahwa pendidikan selayaknya membentuk generasi Indonesia yang cerdas, berkualitas, dan proaktif terhadap perkembangan zaman dan kebutuhan era revolusi industri 4.0.

Merespon hal itu, pemerintah melalui Kementerian Pendidikan dan Kebudayaan, sejak tahun ajaran 2013/2014, mulai memberlakukan Kurikulum 2013 sebagai pengembangan dari Kurikulum Pendidikan sebelumnya. Alasan pengembangan Kurikulum 2013 diantaranya adalah mempersiapkan sumber daya manusia (SDM) melalui pendidikan untuk dapat menghadapi tantangan masa depan berupa globalisasi dan kemajuan teknologi informasi.

Dalam sistem pendidikan, guru merupakan elemen yang memiliki peran sangat penting untuk mencapai tujuan pendidikan dan merealisasikan Kurikulum. Guru yang berinteraksi dan mempersiapkan perserta didik untuk mampu menghadapi tuntutan zaman tersebut. Peraturan Pemerintah (PP) Nomor 74 Tahun 2008 tentang Guru, yang menyatakan tuntutan profesional guru yaitu "Kompetensi guru meliputi kompetensi pedagogik, kompetensi kepribadian, kompetensi sosial, dan kompetensi profesional yang diperoleh melalui pendidikan profesi" (Depdiknas, 2008). Hal ini berimplikasi bahwa guru harus mengembangkan kompetensinya secara berkelanjutan, termasuk jika terjadi transformasi zaman.

Lantas, bagaimana guru mempersiapkan diri untuk memiliki kompetensi era 4.0? Salah satunya, guru dalam bidang pembelajarannya harus mampu beradaptasi bahkan dapat memanfaatkan perkembangan dan kemajuan teknologi yang pesat. Tersedianya informasi dimana saja dan kapan saja berimplikasi bahwa model pembelajaran diarahkan untuk mendorong peserta didik mencari tahu dari berbagai sumber informasi (Litbang Kemdikbud, 2013). Untuk itu, dalam pembelajaran 4.0, guru dapat memanfaatkan teknologi untuk mengembangkan media dan sumber belajar.

Salah satu teknologi pendidikan yang dapat dimanfaatkan untuk menunjang proses pembelajaran adalah program Videoscribe. Program ini dapat dimanfaatkan sebagai media pembelajaran yang bersifat multimedia (mengkombinasikan tampilan visual dan audio) (Rahmawati, Soegimin, \& Kardi, 2016). Selain itu, guru juga dapat memanfaatkan media sosial untuk kepentingan belajar mengajar seperti kemudahan berkomunikasi dan pertukaran informasi yang dibawa serta oleh kemajuan IPTEKS. Media sosial merupakan media online dimana peserta didik dan guru dapat berkomunikasi secara interaktif dan tidak terikat oleh ruang dan waktu. Dengan itu, guru dapat mendiseminasikan multimedia pembelajaran berupa video pembelajaran yang telah dikembangkan ke dalam jejaring sosial misalnya Google Drive, Facebook, Blog, Youtube. Sehingga diharapkan, pembelajaran akan lebih menarik, efisien, dan mudah diakses oleh peserta didik.

Penelitian mengenai pengembangan video pembelajaran dengan menggunakan program Videoscribe telah memberikan informasi bahwa penggunaan video pembelajaran matematika menarik dan mendapat respons positif dari peserta didik (Fadillah \& Bilda, 2019; Nurrohmah, Putra, \& Farida, 2018). Kegiatan pelatihan pengembangan media Videoscribe bagi guru juga menunjukkan bahwa guru dapat mengembangkan media pembelajaran berbantuan Videoscribe untuk menunjang proses pembelajaran matematika (Febrian, Astuti, \& Antika, 2019). Pada kegiatan PkM lanjutan kali ini, kegiatan ditekankan kepada bagaimana guru yang telah mengembangkan multimedia pembelajaran berbantuan Videoscribe dapat memanfaatkan sosial media sebagai alternatif tempat belajar berbasis TIK. Sebagai upaya mendukung pemerintah meningkatkan kreativitas guru dalam memanfaatkan TIK, dosen melalui kegiatan Pengabdian 
kepada Masyarakat, dapat berperan memberikan pelatihan-pelatihan kepada guru untuk menunjang berkualitasnya pelaksanaan proses pembelajaran. Dengan analisis ini, maka kegiatan bertema "Diseminasi online multimedia pembelajaran matematika yang dikembangkan dengan menggunakan Videoscribe" perlu untuk segera dilaksanakan.

\section{Metode}

PkM yang dilaksanakan Febrian, Astuti, \& Antika (2019) telah menghasilkan sejumlah multimedia berbasis Videoscribe yang diciptakan oleh guru MGMP SMA/SMK bidang Matematika di Kabupaten Bintan. Melalui hasil kegiatan tersebut, dilakukan PkM lanjutan dengan penekanan pada upaya diseminasi multimedia. PkM lanjutan ini memiliki metode berupa kegiatan pemaparan materi dan pendampingan kepada guru MGMP SMA/SMK Kabupaten Bintan yang dilaksanakan dalam 1 hari berlokasi di SMA N 1 Kabupaten Bintan. Berdasarkan hasil analisis permasalahan yang ditemukan dan kontribusi yang ditawarkan seperti yang dikemukakan pada bagian sebelumnya, maka bentuk pelaksanaan kegiatan seperti yang diberikan tergambar dalam tabel berikut:

Tabel 1.

Metode pelaksanaan kegiatan

\begin{tabular}{cll}
\hline No & \multicolumn{1}{c}{ Solusi Permasalahan } & \multicolumn{1}{c}{ Metode Pelaksanaan } \\
\hline 1 & $\begin{array}{l}\text { Pengenalan media sosial yang dapat dimanfaatkan } \\
\text { sebagai media pembelajaran }\end{array}$ & Pemaparan Materi, Diskusi dan Demonstrasi \\
\hline 2 & $\begin{array}{l}\text { Pendampingan mendiseminasikan video pembelajaran di } \\
\text { media sosial }\end{array}$ & $\begin{array}{l}\text { Hands on peserta, Pembimbingan intensif, } \\
\text { Presentasi peserta }\end{array}$ \\
\hline
\end{tabular}

Pada akhir kegiatan, tim PkM melakukan evaluasi dengan melakukan 1) observasi keterlibatan peserta PkM selama kegiatan berlangsung; 2) pengecekan produk media pembelajaran yang dikembangkan dengan videoscribe telah didiseminasikan ke sosial media; 3) pemberian angket sebagai evaluasi kerbermanfaatan kegiatan bagi peserta.

\section{Hasil dan Pembahasan}

Kegiatan PkM oleh tim dosen Pendidikan Matematika FKIP UMRAH kepada guru-guru MGMP Matematika SMA dan SMK se-Kabupaten Bintan ini dilaksanakan pada tanggal 13 Agustus 2019 berlokasi di SMA N 1 Bintan Timur. Bentuk kegiatan berupa pendampingan diseminasi multimedia pembelajaran yang dikembangkan dengan bantuan Videoscribe ke dalam sosial media. Setiap guru yang berpartisipasi dalam kegiatan ini menggunakan satu laptop. Model kegiatan yang dipakai dalam kegiatan ini adalah model pendampingan. Metode yang digunakan dalam kegiatan ini terdiri dari:

a) Penyajian materi oleh narasumber mengenai pentingnya mengembangkan multimedia pembelajaran matematika;

b) Penyajian materi oleh narasumber mengenai diseminasi video pembelajaran di sosial media, kelas $e$ learning, dan penyimpanan data online;

c) Praktek teknis pendampingan guru memiliki akun untuk mendiseminasi video pembelajaran matematika;

d) Praktek teknis pendampingan guru untuk diseminasi video pembelajaran ke sosial media/youtube.

Adapun pelaksanaan kegiatan pengabdian adalah sebagai berikut:

1. Registrasi

Sebelum pelaksanaan kegiatan dimulai, peserta diharuskan untuk mengisi daftar hadir yang telah disediakan oleh tim PkM Pendidikan Matematika FKIP UMRAH.

2. Pembukaan 
Kegiatan PkM ini dibuka oleh Wakil Kepala Sekolah SMA N 1 Bintan Timur. Dalam pembukaannya, beliau menyampaikan agar seluruh peserta dapat mengikuti kegiatan dengan fokus dan dapat menggali ilmu yang banyak untuk diterapkan di kelas masing-masing.

3. Pemberian materi

Pemaparan materi PkM ini disampaikan oleh Dosen Pendidikan Matematika FKIP UMRAH, Puji Astuti, S.Pd., M.Sc. Paparan materi berupa bagaimana tuntutan terhadap guru menghadapi era revolusi industri 4.0, dan bagaimana memanfaatkan teknologi untuk pembelajaran.

4. Praktek diseminasi multimedia pembelajaran

Kegiatan PkM ini merupakan kegiatan lanjutan dari rangkaian kegiatan PkM oleh tim dosen Pendidikan Matematika FKIP UMRAH yang dilaksanakan pada subjek yang sama satu minggu sebelumnya. Kegiatan PkM sebelumnya ini bertema "Mengembangkan media berbasis Videoscribe dengan konteks lokal dalam mengajarkan objek matematika". Di kegiatan ini, guru telah dibimbing teknis dalam mengenal program Videoscribe, menginstalasi, memanfaatkan fitur pada program, serta mengembangkan media pembelajaran matematika. Sehingga, pada kegiatan PkM kali ini, guru-guru diasumsikan tidak mengalami kendala untuk mengembangkan media dengan menggunakan Videoscribe dan dapat dilatih untuk mendiseminasikannya ke dalam jejaring sosial.

Praktek diseminasi multimedia pembelajaran dimulai dengan pendampingan kembali membuat video pembelajaran matematika. Bimbingan teknis disampaikan oleh Dosen (Puji Astuti, S.Pd., M.Sc. dan Febrian, S.Pd., M.Sc.) dan dibantu oleh 3 orang mahasiswa (Al Aziz Yanmadika, Pani Ridwan, dan Raja Novia) dari program studi Pendidikan Matematika FKIP UMRAH.

Guru diminta oleh dosen penyaji untuk mengembangkan satu video pembelajaran singkat untuk mengajarkan satu topik materi matematika di laptop masing-masing. Pada pelaksanaannya, terlihat bahwa guru sangat antusias dalam mencoba mengembangkan video pembelajaran matematika yang berisi materi matematika itu sendiri, animasi, gambar, bahkan suara/musik. Dapat diamati oleh dosen penyaji bahwa guru telah dapat menggunakan Videoscribe dengan baik dan lancar.

Setelah pembuatan video pembelajaran dengan program Videoscribe, dosen penyaji masuk ke bimbingan teknis tentang memanfaatkan TIK sebagai media belajar. Adapun TIK yang dapat dimanfaatkan untuk proses pembelajaran adalah sosial media (Whatsapp, Facebook, Telegram), E-learning (Edmodo), Google Classroom, Google Drive, dan Youtube. Guru dapat berperan aktif memanfaatkan fitur-fitur aplikasi di media sosial, salah satunya Facebook untuk berbagi materi berupa link, gambar, maupun video (Sasmito, 2015). Guru-guru diperkenalkan dan didemonstrasikan bagaimana memanfaatkan TIK tersebut untuk proses pembelajaran yang menarik.

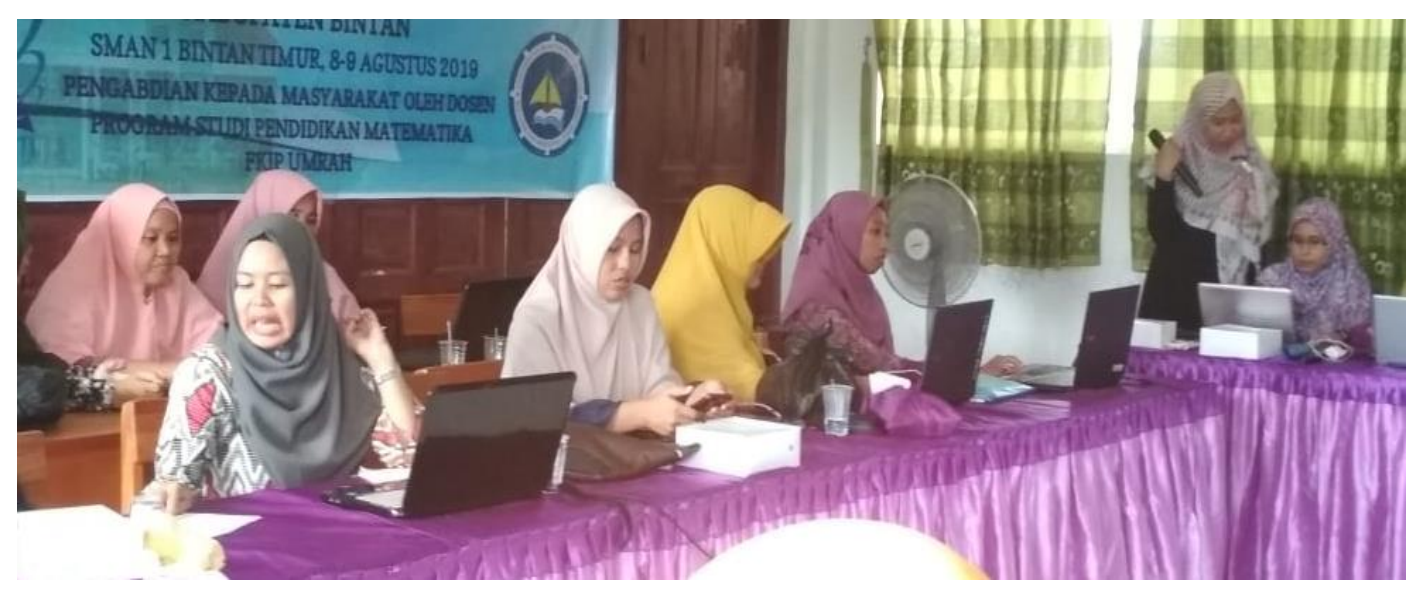

Gambar 1. Pendampingan diseminasi multimedia menggunakan media online 
Kegiatan ini, kemudian, difokuskan mendiseminasikan video pembelajaran yang telah dikembangkan oleh guru peserta PkM ke dalam Youtube. Youtube dipilih karena penggunaannya yang sangat praktis, cocok untuk multimedia pembelajaran, dan sangat familiar di kalangan peserta didik saat ini.

Guru didampingi mulai dari bagaimana membuka laman Youtube di browser, bagaimana memanfaatkan Youtube untuk mencari sumber belajar matematika, bagaimana mendaftarkan diri untuk memiliki akun Youtube, bagaimana mengunggah video pembelajaran ke dalam Youtube Channel, bagaimana mengedit dan merapikan tampilan video pembelajaran, hingga bagaimana membagikan alamat Youtube video pembelajaran yang telah diunggah kepada siswa.

Dari hasil observasi dosen penyaji, guru-guru terlihat sangat antusias dalam mengikuti kegiatan. Diskusi dan tanya jawab antara peserta dan dosen berjalan intens. Hal ini disebabkan karena guru diberikan kesempatan untuk berkreasi membuat video pembelajaran sebagus mungkin. Ditambah lagi, guru dapat membagikan video pembelajaran yang apik dengan menggunakan youtube yang membuat belajar terkemas seperti hiburan. Hal ini dikarenakan, pemanfaatan media pembelajaran untuk proses belajar mengajar dapat memberikan motivasi dan minat belajar (Arsyad, 2016). Adapun link berikut https://www.youtube.com/watch?v=oFxqHiHRPj4 merupakan salah satu contoh hasil video pembelajaran yang dikembangkan oleh guru SMK N 1 Seri Kuala Lobam yang didiseminasikan di sosial media youtube nya sebagai media pembelajaran untuk siswa. Dapat dilihat di dalam multimedia pembelajaran tersebut, guru sudah mampu untuk berkreasi menggunakan dan memanfaatkan fitur-fitur Videoscribe untuk materi Peluang dengan memasukkan tulisan-tulisan, gambar, dan suara. Guru juga dipandang telah mampu membuat transisi video dengan rapi, sehingga multimedia sudah layak untuk dibagikan kepada siswa lewat sosial medianya.
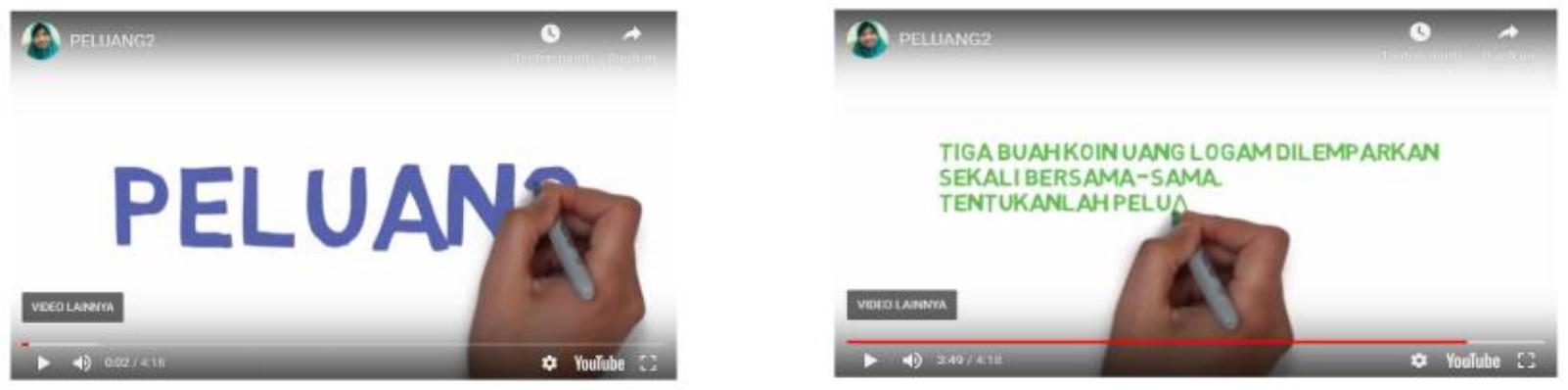

Gambar 2. Hasil eksplorasi peserta PKM didiseminasikan melalui Youtube

Di akhir kegiatan, guru diminta untuk mengisi angket online dengan Google Form. Dari hasil angket diperoleh bahwa $100 \%$ guru peserta kegiatan menyampaikan setuju bahwa pemateri menyampaikan bahan pelatihan dengan baik. Pengalokasian waktu pelatihan pun mendapat respons yang baik dari peserta, $69 \%$ peserta setuju bahwa pembagian waktu untuk materi-materi pendampingan telah dialokasikan dengan baik. Selanjutnya didapatkan respons yang positif dari peserta untuk poin poin lain evaluasi kegiatan, seperti kejelasan mengenai tujuan PkM, susunan materi yang telah disampaikan, kejelasan materi, bagaimana keterlibatan pemateri dalam membantu peserta, bagaimana kegiatan dapat membuat peserta terlibat aktif, kebermanfaatan kegiatan untuk pembelajaran matematika, dan keberlanjutan kegiatan.

\section{Kesimpulan}

Sebagai kesimpulan dari hasil kegiatan PkM oleh tim Pendidikan Matematika FKIP UMRAH ini adalah dapat membantu guru mengembangkan multimedia pembelajaran dengan bantuan videoscribe kemudian didiseminasi ke dalam platform media sosial.

Adapun indikator yang menunjukkan kegiatan ini berjalan dengan baik adalah: 
1. Selama kegiatan berlangsung, guru peserta terlibat $100 \%$ pada awal sampai akhir kegiatan. Selain itu, guru antusias/tertarik belajar sesuatu yang baru bagi mereka, yaitu membagikan laman video pembelajaran lewat Youtube Channel;

2. Dihasilkannya produk diseminasi video pembelajaran oleh guru peserta kegiatan di Youtube Channel;

3. Hasil angket menyampaikan bahwa guru memberikan respons positif dan menginginkan untuk dapat diadakan pelatihan-pelatihan lainnya untuk dapat membantu mengemas pembelajaran yang menarik.

\section{Saran}

Dari kegiatan PkM ini, disarankan agar:

1. Guru dapat mengoptimalkan penggunaan TIK dalam pembelajaran.

2. Guru dapat mengembangkan multimedia pembelajaran matematika dengan menggunakan videoscribe dan mendiseminasikannya untuk topik-topik matematika lain.

3. Guru dapat mengimbaskan hasil pelatihan ini kepada guru-guru lain di sekolahnya.

\section{Referensi}

Arsyad, A. (2016). Media pembelajaran. Jakarta: Raja Grafindo Persada.

Departemen Pendidikan Nasional [Depdiknas]. (2003). Undang-Undang No. 20 tahun 2003 Tentang Sistem Pendidikan Nasional. Jakarta: Depdiknas.

Depdiknas. (2008). Peraturan Pemerintah (PP) Nomor 74 Tahun 2008 tentang Guru. Jakarta: Depdiknas.

Fadillah, A., \& Bilda, W. (2019). Pengembangan video pembelajaran matematika berbantuan aplikasi sSarkoll Videoscribe. Jurnal Gantang, 4(2), 177-182. https://doi.org/https://doi.org/10.31629/jg.v4i2.1369

Febrian, F., Astuti, P., \& Antika, R. (2019). Pelatihan pengembangan media videoscribe dengan konteks lokal dalam mengajarkan objek matematika bagi MGMP SMA Kabupaten Bintan. J-ABDIPAMAS (Jurnal Pengabdian Kepada Masyarakat), 3(2), 101-110.

Litbang Kemdikbud. (2013). Kurikulum 2013: Pergeseran paradigma belajar abad-21. Retrieved from http://litbang.kemdikbud.go.id/index.php/index-berita-kurikulum/243-kurikulum-2013-pergeseranparadigma-belajar-abad-21

Nurrohmah, F., Putra, F. G., \& Farida, F. (2018). Development of Sparkol Video Scribe assisted learning media. Formatif: Jurnal Ilmiah Pendidikan MIPA, 8(3), 233-250.

Rahmawati, F., Soegimin, W. W., \& Kardi, S. (2016). Pengembangan perangkat pembelajaran Fisika model inkuiri terbimbing berbantuan Videoscribe pada materi kalor untuk meningkatkan hasil belajar diswa SMAN 1 Kedungwaru. JPPS (Jurnal Penelitian Pendidikan Sains), 5(2), 1039-1047.

Sasmito, M. (2015). Pemanfaatan media sosial facebook untuk media pembelajaran bahasa Indonesia. Jurnal Metafora, 1(2), 184-198. 